\title{
Why do pre-clinical medical students learn ultrasound? Exploring learning motivation through ERG theory
}

Ting-Cheng Wang ${ }^{1,2}$, Wei-Ting Chen ${ }^{1,2}$, Yi-No Kang ${ }^{3,4}$, Che-Wei Lin ${ }^{3,4,5}$, Chung-Yi Cheng ${ }^{6,7}$, Fat-Moon Suk ${ }^{6,8}$, Hao-Yu Chen ${ }^{5}$, Chin-Wang Hsu' ${ }^{1,2}$, Tsorng-Harn Fong ${ }^{9}$ and Wen-Cheng Huang ${ }^{1,2,3,4,5^{*}}$

\begin{abstract}
Background: In recent years, point-of-care ultrasound (POCUS) has become an essential field of medical education. Bedside ultrasound has become a necessary skill for clinical physicians. Previous studies have already discussed the importance of advancements in ultrasound education. However, learning motivations for ultrasound education have seldom been analyzed in the literature. For medical students, learning ultrasound could have a relevance for their future career. The Existence, Relatedness and Growth (ERG) theory extended Maslow's hierarchy of needs through these three concepts. This theory has been widely used in the workplace to analyze employee job performance but has not yet been applied in medical education. In this study ERG theory was applied to analyze pre-clinical medical students' learning motivation toward ultrasound education.
\end{abstract}

Method: This mixed method study used online questionnaires consisting of open-ended questions as a data collection tool, and based on these results, both qualitative and quantitative analysis were conducted. Participants answered a series of neutral and open-ended questions regarding their motivations to learn ultrasonography. After data collection, a three-step analysis was conducted based on the grounded theory approach. Finally, the results of the thematic coding were used to complete additional quantitative analysis.

Results: The study involved 140 pre-clinical medical students, and their responses fell into 13 specific categories. The analysis demonstrated that students' motivations toward ultrasound education were unbalanced across the three ERG domains $(F=41.257, p<.001)$. Pairwise comparisons showed that students mentioned existence motivation $(\mathrm{MD}=39.3 \% ; p<.001)$ and growth motivation $(\mathrm{MD}=40.7 \% ; p<.001)$ more frequently than relatedness motivation. However, there was no significant difference between existence motivation and growth motivation $(\mathrm{MD}=-1.4 \% ; p=.830)$.

Conclusion: The results revealed that students placed a high value on existence and growth needs rather than relatedness based on the survey. In addition, the findings suggest that ERG theory can be a useful tool to conduct medical education motivation analysis.

Keywords: Ultrasound, Undergraduate, ERG theory, Learning motivation

\footnotetext{
* Correspondence: b001089068@tmu.edu.tw

'Department of Emergency, School of Medicine, College of Medicine, Taipei

Medical University, Taipei, Taiwan

${ }^{2}$ Emergency Department, Department of Emergency and Critical Medicine,

Wan Fang Hospital, Taipei Medical University, No.111, Sec. 3, Xinglong Rd,

Taipei 11696, Taiwan

Full list of author information is available at the end of the article
}

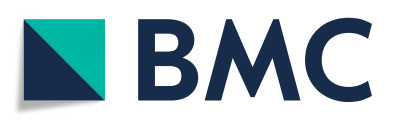

(- The Author(s). 2021 Open Access This article is licensed under a Creative Commons Attribution 4.0 International License, which permits use, sharing, adaptation, distribution and reproduction in any medium or format, as long as you give appropriate credit to the original author(s) and the source, provide a link to the Creative Commons licence, and indicate if changes were made. The images or other third party material in this article are included in the article's Creative Commons licence, unless indicated otherwise in a credit line to the material. If material is not included in the article's Creative Commons licence and your intended use is not permitted by statutory regulation or exceeds the permitted use, you will need to obtain permission directly from the copyright holder. To view a copy of this licence, visit http://creativecommons.org/licenses/by/4.0/ The Creative Commons Public Domain Dedication waiver (http://creativecommons.org/publicdomain/zero/1.0/) applies to the data made available in this article, unless otherwise stated in a credit line to the data. 


\section{Background}

With the emergence of Point-of-care ultrasound (POCUS), ultrasound education has become a significant field of training in both graduate and undergraduate medical education. Ultrasound is a safe and non-invasive diagnostic imaging technology, and the emergence of low-cost, highly portable ultrasonography equipment has extended its use at the bedside. Compared to traditional ultrasound, POCUS emphasizes portability and ease of use. POCUS helps clinicians to make diagnostic decisions based on the interpretation imaging obtained at the bedside. For this reason, it is considered the visual stethoscope of the twenty-first century [1]. POCUS has become a crucial skill for clinical physicians. Previous literature has already discussed the importance of advancements in ultrasound education for medical students $[2,3]$. However, these studies mainly focus on learning outcomes obtained through the design of different learning courses [2]. Many other factors that also affect educational outcomes, including learning motivation, but this factor is rarely addressed in the literature.

Motivation is defined as the organized pattern of the goals, beliefs, and emotions that a person is striving for [4]. In general, discussions of motivation rely on needshierarchy theory or the Motivated Strategies for Learning Questionnaire (MSLQ) [5, 6]. In the medical education field, Knudsen et al. analyzed medical students' learning motivation toward learning ultrasound imaging using the Situational Motivation Scale (SMS) [7]. All of the learning motivation analysis approaches mentioned above are applicable to the general population. However, ultrasound is a tool and skill that is closely related to medical students' future careers. Medical students are very likely to have a specific purpose for learning ultrasound, which stems from considerations related to their future work. Hence, a learning motivation theory was used to target career and job fields. The Existence, Relatedness and Growth (ERG) theory is a motivation analysis framework commonly applied to the study of human motivation in the workplace [8].

Clayton P. Alderfer first proposed ERG theory in 1969 [9]. This theory revised Maslow's hierarchy of needs into 3 domains: Existence, Relatedness, and Growth. Existence refers to concerns about the basics of life [10]. Relatedness is connected to interpersonal needs for mutual trust and respect. Growth is related to achieving selfvalue through creativity, productivity, or one's contributions to the world. ERG theory has been applied to career motivation in many professional fields, yet ERG theory has seldom been used in medical education. In the past, ERG has been widely used in the workplace to analyze employee job performance $[8,11,12]$. This study focused on applying ERG theory to analyze pre-clinical medical students' learning motivation toward ultrasound education.

\section{Method}

The study was conducted through an elective course to understand and analyze learners' motivation to learn bedside ultrasonography, and data was gathered through an online open-ended item questionnaire.

\section{Participants}

This mixed method study enrolled third-year undergraduate medical students (medical training in Taiwan consists of a six-year undergraduate curriculum including four preclinical years followed by two clinical years). The participants were all active students at Taipei Medical University and were recruited via email announcement and voluntarily enrolled in this elective course.

\section{Questionnaire design and development}

The process of the questionnaire development is that 6 medical educators described the possible motivation question first and then the 2 consensus meeting was held. The final questions (2 open-ended questions and 5 binary questions) were determined and online questionnaire was made. The questionnaire consisted of a series of non-leading and open-ended questions. (Supplementary Material) Two primary questions (question 4 and 5) were used for the main analysis: "Why do you want to learn ultrasound?" and "What do you expect from the ultrasound course?" Questions 1, 2 and 3 were demographic questions about prior ultrasound learning experience. Questions 6 and 7 were accessory questions for future curriculum design. In addition, the questionnaires were administered completely online to prevent any bias due to the influence of faculty in a face-to-face setting.

\section{Data analysis}

After data collection, an initial qualitative analysis was conducted before the pre-clinical medical students started the ultrasonography course. After the initial data analysis, quantitative results were produced. No specific framework was developed before data analysis to allow the emergence of a theoretical framework from the responses to the questions about learning motivations, thus avoiding bias from the researchers' subjective tendency and opinion. Three steps for analysis were followed based on grounded theory, an inductive method that provides systematic guidelines for gathering, synthesizing, analyzing and conceptualizing qualitative data for the purpose of theory construction [13]. A feature of this method is the identification of meaningful patterns from qualitative data without any pre-defined framework. This methodology is widely applied in qualitative research to develop an understanding of an unknown phenomenon. In this study, the research team identified relevant elements behind each statement by 
students at the beginning (open-coding step), and the ERG framework was applied later, during the theme coding phase of the analysis. After the initial open coding, the data was compared and potential theories were identified, and it was determined that the ERG framework could appropriately cover every element found in the open coding step. The final coding was completed with ERG theory. The qualitative coding process utilized is summarized as follows:

The analysis was conducted by a 3-member team: A clinical teacher (emergency physician for 10 years subspecializing in emergency ultrasound and medication education), a medical educator (educational faculty member for 7 years subspecializing in evidence-based medicine and medical education), and a senior learner (third-year emergency medicine resident).

\section{First step}

Initial simple identification and classification of learning motivations without a specific framework.

\section{Second step}

The researchers held a consensus meeting for thematic coding based on ERG theory.

\section{Third step}

The evaluators finished the thematic coding of learning motivations.

Finally, the results of the thematic coding were used to complete the quantitative phase of the analysis. Since research members in this study coded the qualitative statements for quantitative analysis, calculation of inter-coder reliability in content analysis approach was determined as an appropriate method for examining the quality of coding in this study. The content inter-coder reliability in this study was calculated based on the formula by Holsti [14], and extension formula for inter-coder reliability among multiple coders was shown below:

$$
\begin{aligned}
& \text { Inter-coder agreement : pi } \\
& \qquad=(2 \times M) /(n 1+n 2)
\end{aligned}
$$

Average mutual agreement $: \mathrm{P}=\sum \mathrm{pi} / \mathrm{N}$

Inter-coder reliability : $\mathrm{R}$

$$
=(\mathrm{N} \times \mathrm{P}) /[1+(\mathrm{N}-1) \mathrm{P}]
$$

$M$ here refers to number of items that each pair coded similarly, and " $n$ " here refers to total number of items each researcher identified. $\mathrm{N}$ here refers to total number of pairs of researchers participating in the content coding.

According to the formula, agreement among pairs ranged from .879 to .958 with average mutual agreement value .910 . Finally, content inter-rater reliability among three team members was .968. After completing the thematic coding, quantitative analysis by calculating the descriptive statistics and using the chi-square test, $\mathrm{t}$-test, and multivariate analysis were applied. Descriptive statistics included counts of background information and motivation domains. Chi-square tests were used to analyze differences in the ultrasound learning experience (yes / no) and sex in each motivation domain (yes / no). The ttest was used to explore the differences in ultrasound learning experience (yes / no) and sex in the sum of the motivation categories in each domain. Multivariate analysis was used to compare the sum of the motivation domains and the sum of the motivation categories. For these continuous analyses, the mean difference (MD) was calculated. These analyses were completed in Statistical Product and Service Solutions version 19 for Microsoft Windows. Eta-square was used to show the multivariate analysis's effect size and set a standard threshold, $p$-value $<0.05$, to judge the statistical significance level. The $95 \%$ confidence interval to indicate the estimated range was reported.

\section{Ethics approval and consent}

The study was approved by Taipei Medical University Joint Institutional Review Board (TMU-JIRB) for Human Experimentation (IRB TMU-JIRB N201909012).

Since data was collected through a standard postcourse survey, the TMU-JIRB suggested that verbal informed consent was sufficient. Informed consent: Informed consent was obtained from all individual participants included in the study.

\section{Results}

The study distributed 140 questionnaires online, and 140 responses were received. Thirty-eight respondents provided answers that were insufficient to conduct a full thematic analysis (such as "interesting" and "want to learn"), but since they met the inclusion criteria, the data from these answers were included in the study for validity analysis.

The research involved 140 pre-clinical medical students, of whom 78 were male, and 62 were female. A total of 19 students had participated in ultrasound learning before the survey. All of them completed the openended online study. The qualitative analysis identified 13 categories within three motivational domains (Table 1). The existence domain encompassed four categories. The category "future work requirement" was the most frequently mentioned motivation for learning ultrasound in the existence domain. The relatedness domain contained only two categories. Regarding the growth domain, students' responses reflected seven categories. No difference 
Table 1 Characteristics and learning experience on each domain

\begin{tabular}{|c|c|c|}
\hline \multirow[b]{2}{*}{ Item } & \multicolumn{2}{|c|}{ Ultrasound learning experience } \\
\hline & $\mathrm{No}^{\mathrm{a}}$ & Yes $^{b}$ \\
\hline \multicolumn{3}{|l|}{ Sex } \\
\hline Male & 69 & 9 \\
\hline Female & 52 & 10 \\
\hline \multicolumn{3}{|l|}{ Existence } \\
\hline E1. Future work requirement & 68 & 14 \\
\hline E2. Want to pass current course (non-specific) & 2 & 1 \\
\hline E3. Want to pass current course (knowledge) & 13 & 3 \\
\hline E4. Want to pass current course (skill) & 1 & 0 \\
\hline Number of students mentioning any motivation about existence & 76 & 15 \\
\hline \multicolumn{3}{|l|}{ Relatedness } \\
\hline R1. Teacher-student & 27 & 5 \\
\hline R2. Not teacher-student & 3 & 1 \\
\hline Number of students mentioning any motivation about relatedness & 30 & 6 \\
\hline \multicolumn{3}{|l|}{ Growth } \\
\hline G1. To be a good doctor in future & 10 & 1 \\
\hline G2. Just want to learn (non-specific) & 21 & 1 \\
\hline G3. Just want to learn (interesting) & 17 & 1 \\
\hline G4. Just want to learn (diverse) & 2 & 2 \\
\hline G5. Just want to learn (improve my current clinical learning) & 9 & 0 \\
\hline G6. Just want to learn (improve my own diagnostic knowledge) & 21 & 3 \\
\hline G7. Just want to learn (improve my own diagnostic skill) & 28 & 5 \\
\hline Number of students mentioning any motivation about growth & 84 & 9 \\
\hline
\end{tabular}

${ }^{\mathrm{a}} n=121 ;{ }^{\mathrm{b}} n=19$

was found in sex or ultrasound learning experience in the three domains (Table 2 and Table 3).

\section{Comparison of the three domains}

Overall, 91 (65\%), 36 (25.71\%), and 93 (66.43\%) students mentioned existence motivation, relatedness motivation, and growth motivation for learning ultrasound (Table 3). The test showed that students' motivations for ultrasound learning were unbalanced $(F=41.257, p<.001)$. Pairwise comparisons showed that they mentioned existence motivation ( $\mathrm{MD}=39.3 \%$; $95 \% \mathrm{CI}, 29.5$ to $49.0 \%$; $p<.001)$ and growth motivation ( $\mathrm{MD}=40.7 \%$; $95 \% \mathrm{CI}$, 28.5 to $52.9 \% ; p<.001)$ more than relatedness motivation. However, there was no significant difference between existence motivation and growth motivation $(\mathrm{MD}=-1.4 \% ; \quad 95 \% \quad \mathrm{CI}, \quad-14.6$ to $11.7 \% ; \quad p=$ .830).(Table 4).

\section{Further comparison of the categories in each motivation domain}

In addition, the sub-motivations in each domain were analyzed (Table 4). Regarding the existence domain, E1 was mentioned more frequently than E2, E3, and E4.
Moreover, E4 was mentioned less than E2 and E3. Regarding the relatedness domain, R1 was mentioned more frequently than R2.

In the growth domain, the seven sub-motivations, and G7was more frequently mentioned than G1, G2, G3, G4, G5, and G6 .

\section{Discussion}

\section{Overview}

This purpose of this study was to apply ERG theory to analyze pre-clinical medical students' learning motivation toward ultrasound education.

Most previous studies focused only on the students' feedback after curriculum implementation to understand the effects of different curriculum designs [15-17]. Most of these studies indicated that motivation increased after curriculum implementation but seldom mentioned students' motivation before participating in the training. This study is the first to provide a detailed exploration of students' motivation before engaging with the curriculum to understand why students want to learn ultrasound. 
Table 2 Sex and learning experience difference in mean frequency by motivation domain

\begin{tabular}{|c|c|c|c|c|c|c|c|}
\hline \multirow{2}{*}{$\begin{array}{l}\text { Domain and } \\
\text { population }\end{array}$} & \multirow[b]{2}{*}{ M } & \multirow[b]{2}{*}{$S D$} & \multirow[b]{2}{*}{$M D$} & \multirow[b]{2}{*}{$t$} & \multirow{2}{*}{$\begin{array}{l}95 \% \\
\text { lower }\end{array}$} & \\
\hline & & & & & & upper & $P$ \\
\hline Existence by sex & & & -0.198 & -1.924 & -0.401 & 0.006 & .056 \\
\hline Male ${ }^{a}$ & .6410 & .58051 & & & & & \\
\hline Female $^{b}$ & .8387 & .63229 & & & & & \\
\hline \multicolumn{3}{|c|}{ Existence by learning experience } & 0.253 & 1.694 & -0.424 & 0.549 & .093 \\
\hline Novice ${ }^{c}$ & .6942 & .60337 & & & & & \\
\hline Experienced $^{d}$ & .9474 & .62126 & & & & & \\
\hline \multicolumn{3}{|c|}{ Relatedness by sex } & 0.027 & 0.365 & -0.121 & 0.175 & .716 \\
\hline Male $^{a}$ & .2692 & .44643 & & & & & \\
\hline Female ${ }^{b}$ & .2419 & .43175 & & & & & \\
\hline \multicolumn{3}{|c|}{ Relatedness by learning experience } & 0.068 & 0.626 & -0.147 & 0.282 & .533 \\
\hline Novice $^{c}$ & .2479 & .43361 & & & & & \\
\hline Experienced $^{d}$ & .3158 & .47757 & & & & & \\
\hline \multicolumn{3}{|l|}{ Growth by sex } & -0.099 & -0.727 & -0.368 & 0.170 & .468 \\
\hline Male ${ }^{a}$ & .8205 & .67888 & & & & & \\
\hline Female ${ }^{b}$ & .9194 & .92857 & & & & & \\
\hline \multicolumn{3}{|c|}{ Growth by learning experience } & -0.208 & -1.059 & -0.597 & 0.181 & .291 \\
\hline Novice ${ }^{c}$ & .8926 & .79374 & & & & & \\
\hline Experienced $^{d}$ & .6842 & .82007 & & & & & \\
\hline \multicolumn{3}{|l|}{ Overall by sex } & -0.269 & -1.778 & -0.569 & 0.030 & .078 \\
\hline Male ${ }^{a}$ & 1.7308 & .83235 & & & & & \\
\hline Female ${ }^{\mathrm{b}}$ & 2.0000 & .95814 & & & & & \\
\hline \multicolumn{3}{|c|}{ Overall by learning experience } & 0.113 & 0.508 & -0.326 & 0.551 & .613 \\
\hline Novice ${ }^{c}$ & 1.8347 & .90689 & & & & & \\
\hline Experienced $^{d}$ & 1.9474 & .84811 & & & & & \\
\hline
\end{tabular}

a. $n=78$; b. $n=62$; c. $\mathrm{n}=121$; d. $n=19$. M, mean; MD, mean difference; SD, standard deviation

Table 3 Number of students describing specific motivation domains by sex and learning experience

\begin{tabular}{|c|c|c|c|c|c|c|c|c|}
\hline \multirow[b]{2}{*}{ Item } & \multicolumn{2}{|l|}{ Sex } & \multirow{2}{*}{$\begin{array}{l}\text { Chi- } \\
\text { square }\end{array}$} & \multirow[b]{2}{*}{$p$} & \multicolumn{2}{|c|}{ Ultrasound learning experience } & \multirow{2}{*}{$\begin{array}{l}\text { Chi- } \\
\text { square }\end{array}$} & \multirow[b]{2}{*}{$p$} \\
\hline & Male $^{a}$ & Female $^{b}$ & & & $\overline{\text { No }^{c}}$ & Yes $^{d}$ & & \\
\hline Sex & & & & & & & 0.621 & .431 \\
\hline Male & - & - & - & - & 69 & 9 & & \\
\hline Female & - & - & & & 52 & 10 & & \\
\hline Existence & & & 1.742 & .187 & & & 1.88 & .170 \\
\hline No mentioned & 31 & 18 & & & 45 & 4 & & \\
\hline Mentioned & 47 & 44 & & & 76 & 15 & & \\
\hline Relatedness & & & 0.135 & .714 & & & 0.396 & .529 \\
\hline No mentioned & 57 & 47 & & & 91 & 13 & & \\
\hline Mentioned & 21 & 15 & & & 30 & 6 & & \\
\hline Growth & & & 0.004 & .947 & & & 3.581 & .058 \\
\hline No mentioned & 26 & 21 & & & 37 & 10 & & \\
\hline Mentioned & 52 & 41 & & & 84 & 9 & & \\
\hline
\end{tabular}

${ }^{a} n=78 ;{ }^{b} n=62 ;{ }^{c} n=121 ;{ }^{d} n=19$ 
Table 4 Pairwise comparison of motivations

\begin{tabular}{|c|c|c|c|c|c|c|}
\hline \multirow[b]{2}{*}{ Comparisons } & \multirow[b]{2}{*}{ MD } & \multicolumn{2}{|l|}{$95 \% \mathrm{Cl}$} & \multirow[b]{2}{*}{$F$} & \multirow[b]{2}{*}{$p$} & \multirow{2}{*}{$\begin{array}{l}\text { Eta- } \\
\text { square }\end{array}$} \\
\hline & & Lower & Upper & & & \\
\hline Multivariate tests (overall) & & & & 41.257 & $<.001$ & .374 \\
\hline Existence vs Relatedness & $0.393^{* * *}$ & 0.295 & 0.490 & & & \\
\hline Existence vs Growth & -0.014 & -0.146 & 0.117 & & & \\
\hline Relatedness vs Growth & $-0.407^{* * *}$ & -0.529 & -0.285 & & & \\
\hline Multivariate tests (existence) & & & & 69.996 & $<.001$ & .605 \\
\hline E1 vs E2 & $.471^{* * *}$ & .372 & .571 & & & \\
\hline E1 vs E3 & $.564^{* * *}$ & .476 & .652 & & & \\
\hline E1 vs E4 & $.579 * * *$ & .496 & .661 & & & \\
\hline E2 vs E3 & $.093^{* *}$ & .033 & .153 & & & \\
\hline E2 vs E4 & $.107^{* * *}$ & .055 & .159 & & & \\
\hline E3 vs E4 & .014 & -.014 & .043 & & & \\
\hline Multivariate tests (relatedness) & & & & 25.605 & $<.001$ & .156 \\
\hline R1 vs R2 & $.200^{* * *}$ & .122 & .278 & & & \\
\hline Multivariate tests (growth) & & & & 9.540 & $<.001$ & .299 \\
\hline G1 vs G2 & -.079 & -.154 & -.003 & & & \\
\hline G1 vs G3 & -.050 & -.126 & .026 & & & \\
\hline G1 vs G4 & .050 & -.004 & .104 & & & \\
\hline G1 vs G5 & .014 & -.046 & .074 & & & \\
\hline G1 vs G6 & -.093 & -.170 & -.015 & & & \\
\hline G1 vs G7 & -.157 & -.238 & -.076 & & & \\
\hline G2 vs G3 & .029 & -.056 & .113 & & & \\
\hline G2 vs G4 & .129 & .066 & .191 & & & \\
\hline G2 vs G5 & .093 & .018 & .168 & & & \\
\hline G2 vs G6 & -.014 & -.108 & .080 & & & \\
\hline G2 vs G7 & -.079 & -.181 & .024 & & & \\
\hline G3 vs G4 & .100 & .039 & .161 & & & \\
\hline G3 vs G5 & .064 & -.009 & .137 & & & \\
\hline G3 vs G6 & -.043 & -.130 & .044 & & & \\
\hline G3 vs G7 & -.107 & -.207 & -.008 & & & \\
\hline G4 vs G5 & -.036 & -.086 & .015 & & & \\
\hline G4 vs G6 & -.143 & -.214 & -.072 & & & \\
\hline G4 vs G7 & -.207 & -.286 & -.128 & & & \\
\hline G5 vs G6 & -.107 & -.176 & -.039 & & & \\
\hline G5 vs G7 & -.171 & -.254 & -.089 & & & \\
\hline G6 vs G7 & -.064 & -.147 & .019 & & & \\
\hline
\end{tabular}

${ }^{+} p<.10 ;{ }^{*} p<.05 ;{ }^{* *} p<.01 ;{ }^{* * *} p<.001 ; \mathrm{Cl}$, confidence interval; $\mathrm{MD}$, mean difference

\section{Learning theories and motivation}

There are several learning theories related to adult learning [18]. Focusing on learning motivation, these contemporary theories in medical education include the expectancy-value [19], attribution [20], social-cognitive [21], goal orientation $[4,22]$, and self-determination theories [23]. These previously described findings seem unsuitable for the analysis of qualitative data from learners.
Unlike traditional theories, ERG theory can be applied to extract more qualitative data from learners' responses.

\section{Key findings}

The study suggests that existence needs and growth needs were more significant than relatedness needs concerning students' motivation to learn ultrasound. The findings indicate that students learn ultrasonography 
voluntarily because they consider ultrasound skills to be closely connected to their future careers as doctors. In the existence needs subgroup analysis, most students mentioned the words "future" and "clinical". In particular, the categories (E1) Future work requirement and (G7) Just want to learn (improve diagnostic skills) dominated, even though ultrasound training is not required for medical undergraduates in Taiwan.

\section{Participant learning motivation}

None of the students in the study had started their clinical training, and had little previous ultrasound experience. However, they showed great interest in learning because they anticipated future applications of ultrasound. This interest suggests that students are already aware of the increasing importance of bedside ultrasonography, which has become a trend in recent years. Concerning growth needs, learning ultrasonography skills has great importance for students. This phenomenon may be related to the fact that unlike X-ray and computed tomography $(\mathrm{CT})$ examinations, ultrasound is an operator-dependent diagnostic tool. Ultrasonographic skills development is of great importance in ultrasound education and is also affected by learning motivation. Previous studies on ultrasound education mainly focus on performance [2, 15-17]. Unfortunately, the learning motivations for learning ultrasound were not well established.

\section{Motivation analysis}

In performing further motivation analysis, some results were unexpected. The first finding was that relatedness needs were less salient than existence needs and growth needs. Relatedness needs were expected be as important as the other types of needs, particularly in the Taiwanese cultural context in which Confucianism has a farreaching influence. Interpersonal relationships are vital and affect learning motivation in individuals of Chinese background [24]. Surprisingly, the research did not reflect this, possibly because of students' awareness that ultrasound skills were essential for their future work. The researchers concluded this was not due to a reduction in the relatedness needs in Chinese culture but that the widespread nature of ultrasound applications has promoted increased existence and growth needs. Students' learning motivation is thus less affected by interpersonal factors.

\section{Sex and motivation}

The second finding was that relatedness needs did not differ between the sexes. It was initially assumed that sex would influence the motivation of medical students to learn ultrasound. Previous studies have suggested that traditional sex role stereotypes dictate that men seem more inclined toward mathematics, science and rationality. In contrast, women have a more substantial interest in language arts and writing [25]. Thus, sex may also affect learning motivation. However, the research revealed that there were no sex differences concerning the relatedness motivation to learn sonoanatomy. This result may be explained by Bandura's Triadic Theory of Learning. Human learning is affected by environmental factors, personal factors, and behavioral factors rather than by a single intrinsic tendency and is influenced by a person's surroundings [26]. Therefore, sex is not sufficient to influence the motivation of medical students to learn ultrasound. The results strengthen the environmental explanation (the increasing trend in ultrasound applications in clinical practice) mentioned above. Ultrasound is a crucial skill in students' future careers.

\section{ERG theory in ultrasonography learning}

Because of the use of different training models and differences in medical undergraduates' needs and perspectives, ERG theory was employed to explore pre-clinical medical students' motivation to learn clinical skills. The analysis revealed that pre-clinical medical students are more focused on existence and growth needs. Thus, meeting these needs when developing a new course or curriculum should be emphasized. In addition, it is necessary to motivate students and offer future-oriented learning that is effective and efficient. This qualitative analytic study following grounded theory methodology confirms that ERG theory can be applied to explore learning motivation for professional development. The ERG theory may also be adapted to analyze learners' motivation in other healthcare professions.

\section{Limitations}

First, the online questionnaire's non-directed, openended nature led to some replies being ambiguous, and their true meaning could not be ascertained. Thus, the interpretation may not have necessarily represented the respondents' actual thoughts. Second, the study was conducted in single institution and in a culturally homogeneous group. The diversity of the sample was insufficient to make more profound generalizations to other cultural contexts. Medical students' motivation to learn sonoanatomy may differ by school, region, or culture. Third, this research did not consider individual medical students' background differences and their potential impact on learning motivation.

\section{Conclusion}

This study revealed several meaningful findings. First, students placed a very high value on existence needs and growth needs but not on relatedness needs. Second, in our subgroup analysis, no sex difference was noted with 
respect to relatedness. Based on this survey of learning motivation for ultrasonography skills, applying ERG theory in the context of medical student and medical personnel education to analyze students' skill-learning motivation could lead to a better understanding. of learners' interest in developing their skills.

\section{Abbreviations}

POCUS: Point of Care Ultrasound; ERG: Existence, Relatedness, Growth; MSLQ: Motivated Strategies for Learning Questionnaire; SMS: Situational Motivation Scale; MD: Mean Difference; CT: Computed Tomography

\section{Supplementary Information}

The online version contains supplementary material available at https:/doi. org/10.1186/s12909-021-02869-4.

\section{Additional file 1}

\section{Acknowledgements}

Special thanks to Miss Hung-Chen Chen who is the administrator in Center for Education in Medical Simulation (CEMS), Taipei Medical University, Taiwan for collections of students' data.

\section{Authors' contributions}

TCW, WTC, YNK, WCH contributed to the design of the study, collection and analysis of data and drafting the manuscript. CWL, FMS, CYC, HYC, CWH, THF participated in the critical review of the manuscript, and contributed analysis tools, and made substantial contributions to interpretation of data. All authors read and approved the final manuscript.

\section{Funding}

The present study is funded by Taipei Medical University, Wan Fang Hospital Research Grant 107-wf-eva-05.

\section{Availability of data and materials}

The datasets used and/or analyzed during the current study are available from the corresponding author on reasonable request.

\section{Declarations}

Ethics approval and consent to participate

The study was approved by Taipei Medical University Joint Institutional Review Board (TMU-JIRB) for Human Experimentation. The number of IRB was TMU-JIRB N201909012.

Since data was collected through a standard post-course survey, the TMUJIRB suggested that verbal informed consent was sufficient. Informed consent: Informed consent was obtained from all individual participants included in the study

\section{Consent for publication}

Not applicable.

\section{Competing interests}

The authors declare no competing financial interest.

\section{Author details}

${ }^{1}$ Department of Emergency, School of Medicine, College of Medicine, Taipe Medical University, Taipei, Taiwan. ${ }^{2}$ Emergency Department, Department of Emergency and Critical Medicine, Wan Fang Hospital, Taipei Medical University, No.111, Sec. 3, Xinglong Rd, Taipei 11696, Taiwan. ${ }^{3}$ Department of Education and Humanities in Medicine, School of Medicine, College of Medicine, Taipei Medical University, Taipei, Taiwan. ${ }^{4}$ Department of Education, Wan Fang Hospital, Taipei Medical University, Taipei, Taiwan. ${ }^{5}$ Center for Education in Medical Simulation, Taipei Medical University, Taipei, Taiwan. ${ }^{6}$ Department of Internal Medicine, School of Medicine, College of Medicine, Taipei Medical University, Taipei, Taiwan. ${ }^{7}$ Department of Internal Medicine, Division of Nephrology, Wan Fang Hospital, Taipei Medical University, Taipei, Taiwan. ${ }^{8}$ Department of Internal Medicine, Division of
Gastroenterology, Wan Fang Hospital, Taipei Medical University, Taipei, Taiwan. ${ }^{9}$ Department of Anatomy and Cell Biology, School of Medicine, College of Medicine, Taipei Medical University, Taipei, Taiwan.

Received: 27 July 2020 Accepted: 6 August 2021

Published online: 19 August 2021

\section{References}

1. Gillman LM, Kirkpatrick AW. Portable bedside ultrasound: the visual stethoscope of the 21st century. Scand J Trauma Resusc Emerg Med. 2012; 20(1):18. https://doi.org/10.1186/1757-7241-20-18.

2. Feilchenfeld Z, Dornan T, Whitehead C, Kuper A. Ultrasound in undergraduate medical education: a systematic and critical review. Med Educ. 2017;51(4):366-78. https://doi.org/10.1111/medu.13211.

3. Wilson SP, Mefford JM, Lahham S, Lotfipour S, Subeh M, Maldonado G, et al. Implementation of a 4-Year Point-of-Care Ultrasound Curriculum in a Liaison Committee on Medical Education-Accredited US Medical School: J Ultrasound Med. 2017:36:321-5.

4. Ford M. Motivating Humans: Goals, Emotions, and Personal Agency Beliefs. 2455 Teller Road, Thousand Oaks California 91320 United States : SAGE Publications, Inc.; 1992

5. Pillay HK, Boulton-Lewis GM. Investigating cross-cultural variation in conceptions of learning and the use of self-regulated strategies; 2000.

6. Tang M, Neber $\mathrm{H}$. Motivation and self-regulated science learning in highachieving students: differences related to nation, gender, and grade-level. High Ability Studies. 2008;19(2):103-16. https://doi.org/10.1080/13598130802 503959

7. Knudsen L, Nawrotzki R, Schmiedl A, Mühlfeld C, Kruschinski C, Ochs M. Hands-on or no hands-on training in ultrasound imaging: a randomized trial to evaluate learning outcomes and speed of recall of topographic anatomy. Anat Sci Educ. 2018;11(6):575-91. https://doi.org/10.1002/ase.1792.

8. Caulton JR. The development and use of the theory of ERG: a literature review. Emerging Leadership Journeys. 2012;5:2-8.

9. Alderfer CP. An empirical test of a new theory of human needs. Organizational Behavior Human Performance. 1969:4(2):142-75. https://doi. org/10.1016/0030-5073(69)90004-X.

10. Maslow AH. A theory of human motivation. Psychol Rev. 1943:50(4):370-96. https://doi.org/10.1037/h0054346

11. Ullah MH, Khan MNU, Murtaza A, Din MNU. Staff Development Needs In Pakistan Higher Education. J Coll Teach Learning (TLC). 2011:8.

12. Kaliprasad $M$. The human factor I: attracting, retaining, and motivating capable people. Cost Engineering. 2006:48:20.

13. Charmaz K. Grounded theory: methodology and theory construction. In International Encyclopedia of the Social \& Behavioral Sciences. 2001. p. $6396-9$

14. Holsti OR. Content analysis for the social sciences and humanities. Reading MA: Addison-Wesley (content analysis). 1969.

15. Gogalniceanu P, Sheena Y, Kashef E, Purkayastha S, Darzi A, Paraskeva P. Is basic emergency ultrasound training feasible as part of standard undergraduate medical education? J Surg Educ. 2010;67(3):152-6. https:// doi.org/10.1016/j.jsurg.2010.02.008.

16. Davis JJ, Wessner CE, Potts J, Au AK, Pohl CA, Fields JM. Ultrasonography in undergraduate medical education: a systematic review. J Ultrasound Med. 2018:37(11):2667-79. https://doi.org/10.1002/jum.14628.

17. Goodcoff A, Keane D, Bialczak A, Ziner E, Hanna JB. Point-of-care ultrasonography integration in undergraduate medical education: a student-driven approach. J Am Osteopath Assoc. 2019;119(3):e11-6. https:// doi.org/10.7556/jaoa.2019.033.

18. Cook DA, Artino AR Jr. Motivation to learn: an overview of contemporary theories. Med Educ. 2016;50(10):997-1014. https://doi.org/10.1111/medu.13 074.

19. Wigfield A, Eccles JS. Expectancy-value theory of achievement motivation Contemp Educ Psychol. 2000;25(1):68-81. https://doi.org/10.1006/ceps.1 999.1015

20. Weiner B. An attributional theory of achievement motivation and emotion Psychol Rev. 1985:92(4):548-73. https://doi.org/10.1037/0033-295X.92.4.548.

21. Bandura A. Social foundations of thought and action. Englewood Cliffs 1986:1986.

22. Locke EA, Latham GP. Building a practically useful theory of goal setting and task motivation: a 35-year odyssey. Am Psychol. 2002:57(9):705-17. https://doi.org/10.1037/0003-066X.57.9.705. 
23. Ryan RM, Deci EL. Self-determination theory and the facilitation of intrinsic motivation, social development, and well-being. Am Psychol. 2000;55(1):6878. https://doi.org/10.1037/0003-066X.55.1.68.

24. Watkins DA, Biggs JB. The Chinese learner: cultural, psychological, and contextual influences. ERIC; 1996.

25. Meece JL, Glienke BB, Burg S. Gender and motivation. J Sch Psychol. 2006; 44(5):351-73. https://doi.org/10.1016/j.jsp.2006.04.004.

26. Bandura A, McClelland DC. Social learning theory. Englewood cliffs Prentice Hall; 1977.

\section{Publisher's Note}

Springer Nature remains neutral with regard to jurisdictional claims in published maps and institutional affiliations.

Ready to submit your research? Choose BMC and benefit from:

- fast, convenient online submission

- thorough peer review by experienced researchers in your field

- rapid publication on acceptance

- support for research data, including large and complex data types

- gold Open Access which fosters wider collaboration and increased citations

- maximum visibility for your research: over $100 \mathrm{M}$ website views per year

At $\mathrm{BMC}$, research is always in progress.

Learn more biomedcentral.com/submissions 